\title{
The prognostic significance of tumor deposits in patients with head and neck squamous cell carcinomas
}

\author{
Shuting Yu ${ }^{1}$, Yingying Zhu ${ }^{1}$, Xiaohua Shi ${ }^{2}$,Wenwen Diao ${ }^{1}$, Xiaoli Zhu ${ }^{1}$, Zhiqiang Gao ${ }^{1}$, Xingming Chen ${ }^{1}$ \\ ${ }^{1}$ Department of Otolaryngology-Head and Neck Surgery, Peking Union Medical College Hospital, Peking Union Medical College and Chinese \\ Academy of Medical Sciences, Beijing, China; ${ }^{2}$ Department of Pathology, Peking Union Medical College Hospital, Peking Union Medical College \\ and Chinese Academy of Medical Sciences, Beijing, China \\ Contributions: (I) Conception and design: X Chen, S Yu, Z Gao; (II) Administrative support: X Chen, Z Gao; (III) Provision of study materials or \\ patients: S Yu, W Diao, X Zhu; (IV) Collection and assembly of data: S Yu, X Shi, W Diao, X Zhu; (V) Data analysis and interpretation: S Yu, Y Zhu; \\ (VI) Manuscript writing: All authors; (VII) Final approval of manuscript: All authors. \\ Correspondence to: Xingming Chen, MD. Department of Otolaryngology-Head and Neck Surgery, Peking Union Medical College Hospital, \\ Peking Union Medical College and Chinese Academy of Medical Sciences, No. 1, Shuaifuyuan, Wangfujing, Beijing 100730, China. \\ Email: xingming.chen@hotmail.com.
}

\begin{abstract}
Background: A tumor deposit (TD) is a phenomenon that has not been well studied in head and neck squamous cell carcinoma (HNSCC) but might have prognostic significance. The present study was conducted to explore the presence and the prognostic significance of TDs in patients with HNSCCs.

Methods: Six hundred forty-two pathologically confirmed HNSCC patients with neck dissection samples were enrolled in this retrospective study. Patients were followed up and evaluated every 3 months in the first 3 years after surgery, and every 6 months thereafter by physical examination and computed tomography (CT)/ magnetic resonance imaging (MRI) scans. The five-year overall survival (OS), disease-specific survival (DSS), and recurrence-free survival (RFS) were compared in the TD and non-TD groups using multivariable analyses and propensity score matching (PSM) methodology (1:1).

Results: The 5-year OS, DSS, and RFS rate of all patients was 77.3\%, 80.6\%, and 71.9\%, respectively. In the multivariable analyses, poorer rates of $\mathrm{OS}(\mathrm{HR}=2.345, \mathrm{P}<0.001)$, DSS ( $\mathrm{HR}=2.818, \mathrm{P}<0.001)$, and RFS ( $H R=2.536, P<0.001)$ were observed in the TD versus the non-TD group. In the PSM cohort, eightyone patients who had TDs were paired with 70 patients without TDs. Significantly diminished rates of DSS $(\mathrm{P}=0.040)$ and RFS $(\mathrm{P}=0.004)$ were found in the TD versus the non-TD group.

Conclusions: In response to sparse reports regarding TDs in HNSCCs, the present study proposes the $\mathrm{TD}$ as an independent poor prognostic factor meriting further research because of its association with diminished OS, DSS, and RFS rates.
\end{abstract}

Keywords: Head and neck carcinoma; tumor deposits; prognostic significance; survival; propensity score matching

Submitted May 30, 2020. Accepted for publication Dec 16, 2020.

doi: 10.21037/atm-20-4369

View this article at: http://dx.doi.org/10.21037/atm-20-4369

\section{Introduction}

Approximately 880,000 patients are diagnosed with some type of head and neck cancer, and approximately 450,000 patients expire due to the disease each year (1). According to global cancer statistics in 2018, head and neck cancer ranks seventh among all cancers (1), and squamous cell carcinomas account for more than $90 \%$ of head and neck cancer (2). Several independent prognostic factors have been identified in head and neck squamous cell carcinoma (HNSCC), including extranodal extension, positive margins, and perineural invasion, among others. However, the prognostic value of tumor deposits (TDs) in HNSCC has rarely been mentioned in the literature. 
Since the 1930s, the concept of the TD was introduced as small bits of tumor in pericolorectal adipose tissue in colorectal cancer (3). TDs were defined by pathologists as tumor nodules located a distance from but in the lymphatic drainage of the primary tumor. No morphological features of lymph nodes should be detected (4). Several studies have shown that TDs are related to an adverse prognosis in colorectal carcinoma (5-9). Hence, they were included in the TNM staging system for colorectal carcinomas since 2010 (10). Additionally, the predictive value of TDs has also been studied in gastric carcinomas $(11,12)$, pancreatic carcinomas, and cholangiocarcinomas (13).

Considering that few studies in the literature have focused on TDs in squamous cell carcinoma (SCC), especially HNSCC, their independent prognostic significance is still unknown. The present study aimed to identify TDs in HNSCC samples and to explore their correlations with survival. We present the following article in accordance with the STROBE reporting checklist (available at: http://dx.doi.org/10.21037/atm-20-4369).

\section{Methods}

\section{Patient population}

From January 2010 to December 2018, 642 patients were continuously enrolled at Peking Union Medical College Hospital. Inclusion criteria were as follows: (I) pathologically confirmed, previously untreated HNSCC undergoing radical resection; (II) neck dissection materials available. The exclusion criteria were as follows: (I) loss during follow-up; (II) presence of other malignant tumors. TNM stages of all participants were evaluated according to the American Joint Committee on Cancer (AJCC) in 2017. Clinical information such as age, gender, adult comorbidity score, tumor site, and tobacco and alcohol consumption were obtained from the medical history of the participants.

Smokers were delimited as patients who smoked more than 100 cigarettes in their lifetime; otherwise, they were delimited as never smokers. Drinkers were delimited as those who consumed alcohol at least once a week for over a year; whereas never drinkers had consumed less. The adult comorbidity score was graded by the Adult Comorbidity Evaluation 27 index, which has been validated as a dependable comorbidity index for patients with head and neck cancer (14).

\section{Surgical procedures}

Curative surgery was performed in all patients in this study. Primary tumor resection and neck dissection were accomplished following accepted criteria for adequate resection according to the location and stage of the tumor.

\section{Histological analysis}

Pathological data such as histopathologic grade, lymph node metastasis, extranodal extension, positive margins, perineural invasion, and lymphovascular invasion were extracted from pathological reports. Original pathology slides were re-examined by two pathologists who were blinded to the purpose of the study. TDs were defined as tumor nodules in the lymphatic drainage area of the primary tumor, away from the tumor and with no morphological features of lymph nodes.

\section{Patient follow-up}

Patients were followed up and evaluated every 3 months in the first 3 years after surgery and every 6 months thereafter by physical examination and computed tomography (CT)/magnetic resonance imaging (MRI) scans. All patients were followed up for at least 1 year or until death. Patients were regarded as recurrence-free if cancer absence was recorded on the last visit. Recurrences were diagnosed by biopsy, positron emission tomography (PET), bone scan, or CT/MRI.

Overall survival (OS) was assigned as the primary endpoint, which was the time from surgery to the time of death due to any reason or last follow-up. Recurrencefree survival (RFS) and disease-specific survival (DSS) were assigned as the secondary end-points. DSS was the time from surgery to the time of death from primary disease or last follow-up, and RFS was the time from surgery to the time of recurrence or last follow-up.

\section{Statistical analysis}

The baseline characteristics of the TD group and the nonTD group are presented as the number of patients and percentages. They were then compared using the Pearson $\chi^{2}$ test. Survival analyses of the two groups were compared with Kaplan-Meier methodology and the log-rank test. 
Unadjusted univariable and multivariable Cox proportional hazards models were used to estimate the prognostic value of TDs and other pathologic features. To strengthen the stability of the study findings, propensity score matching (PSM) was applied herein as a sensitivity analysis. Nearest neighbor 1:1 matching was applied in the matching for the TD and non-TD groups. Matching covariates included tumor site, age, gender, tobacco and alcohol consumption, adult comorbidity score, differentiation grade, pathologic T stage ( $\mathrm{pT}$ ), pathologic $\mathrm{N}$ stage $(\mathrm{pN})$, pathologic stage, extranodal extension, positive margins, perineural invasion, and lymphovascular invasion. All statistical tests were twosided, and $\mathrm{P}$ values $<0.05$ were considered statistically significant. SPSS version 23.0 (IBM Corporation, USA) was applied for the statistical analyses.

\section{Ethical statement}

The study was conducted in accordance with the Declaration of Helsinki (as revised in 2013). The current study was approved by the Ethics Committee of Peking Union Medical College Hospital (NO: S-K1243), Peking Union Medical College and Chinese Academy of Medical Sciences, Beijing, China. Individual consent for this retrospective analysis was waived. The study outcomes will not affect the future management of the patients.

\section{Results}

\section{Baseline characteristics}

A total of 642 patients were enrolled in this study from January 2010 to December 2018. Most of the patients (50.8\%) were between 56 to 70 years old. The male:female ratio was 6.6:1 (557 males:85 females). The larynx (49.5\%) and oral cavity $(29.3 \%)$ were the predominant tumor sites in HNSCC patients in this study. Most patients (75.1\%) were diagnosed with stage III-IV disease. TDs were found in $81(12.6 \%)$ patients.

As presented in Table 1, no significant differences were found between the two groups regarding age, tobacco consumption, comorbidity score, histopathologic grade, extranodal extension, positive margins, or perineural invasion. Compared with the non-TD group, the TD group had a significantly higher proportion of hypopharynx SCC $(\mathrm{P}=0.001)$, males $(\mathrm{P}=0.018)$, and drinkers $(\mathrm{P}=0.034)$. Patients with TDs were also more likely to exhibit lymphovascular invasion $(\mathrm{P}<0.001)$, a higher $\mathrm{pT}(\mathrm{P}=0.002), \mathrm{pN}(\mathrm{P}<0.001)$, and pathologic stage $(\mathrm{P}<0.001)$.

\section{Treatment outcomes}

The median follow-up time for the whole cohort was 44 months. The median OS, DSS, and RFS time was 44, 44, and 39 months, respectively. Among 642 patients, $510(79.4 \%)$ were alive. One hundred eight patients (TD, $\mathrm{n}=48$; non-TD, $\mathrm{n}=60$ ) expired due to primary disease. Twenty-four patients expired because of intercurrent diseases. For the whole cohort, the 3- and 5-year OS rate was $82.1 \%$ and $77.3 \%$, respectively. The 3 - and 5 -year DSS rate was $85.0 \%$ and $80.6 \%$, respectively.

The 3-and 5-year RFS rate of the entire cohort was $74.7 \%$ and $71.9 \%$, respectively. The median survival time for patients with recurrence was 8 months (range: 0-78 months). Therefore, the patients could still live for several months after diagnosis of recurrence. However, related symptoms such as infection, dyspnea, dysphagia, and pain occurred in most patients with recurrence.

As shown in Figure 1, the non-TD group had higher OS $(\mathrm{P}<0.001)$, DSS $(\mathrm{P}<0.001)$, and RFS $(\mathrm{P}<0.001)$ rates. The 5 -year OS rate was $49.5 \%$ and $80.9 \%$ in the TD and nonTD group, respectively. The 5 -year DSS rate was $49.5 \%$ in the TD group compared with $84.8 \%$ in the non-TD group. The 5 -year RFS rate was $35.7 \%$ and $77.0 \%$ in the TD and non-TD group, respectively.

\section{Univariable and multivariable analyses}

As presented in Table 2, differentiation, $\mathrm{pT}$, pN, pathologic stage, extranodal extension, positive margins, perineural invasion, lymphovascular invasion, and TDs were included to compare the predictive power of TDs with other pathologic factors. TDs were associated with reduced OS, DSS, and RFS rates in the univariable analysis. In the multivariable analysis, patients in the TD group were associated with reduced OS (HR $=2.345$; 95\% CI: $1.533-$ 3.587; $\mathrm{P}<0.001$ ), DSS (HR $=2.818$; 95\% CI: $1.828-4.345$; $\mathrm{P}<0.001)$, and RFS (HR $=2.536$; 95\% CI: $1.762-3.650$; $\mathrm{P}<0.001)$ rates. Differentiation, pathologic grade, perineural invasion, and lymphovascular invasion were independent predictive factors for OS, DSS, and RFS along with TDs.

\section{Propensity score matching}

All the characteristics in Table 1 were chosen as independent variables for PSM. Using a matching score of 1:1 and 
Page 4 of 12

Yu et al. The prognostic significance of tumor deposits in HNSCC

Table 1 Baseline characteristics of HNSCC patients between the TD and non-TD group

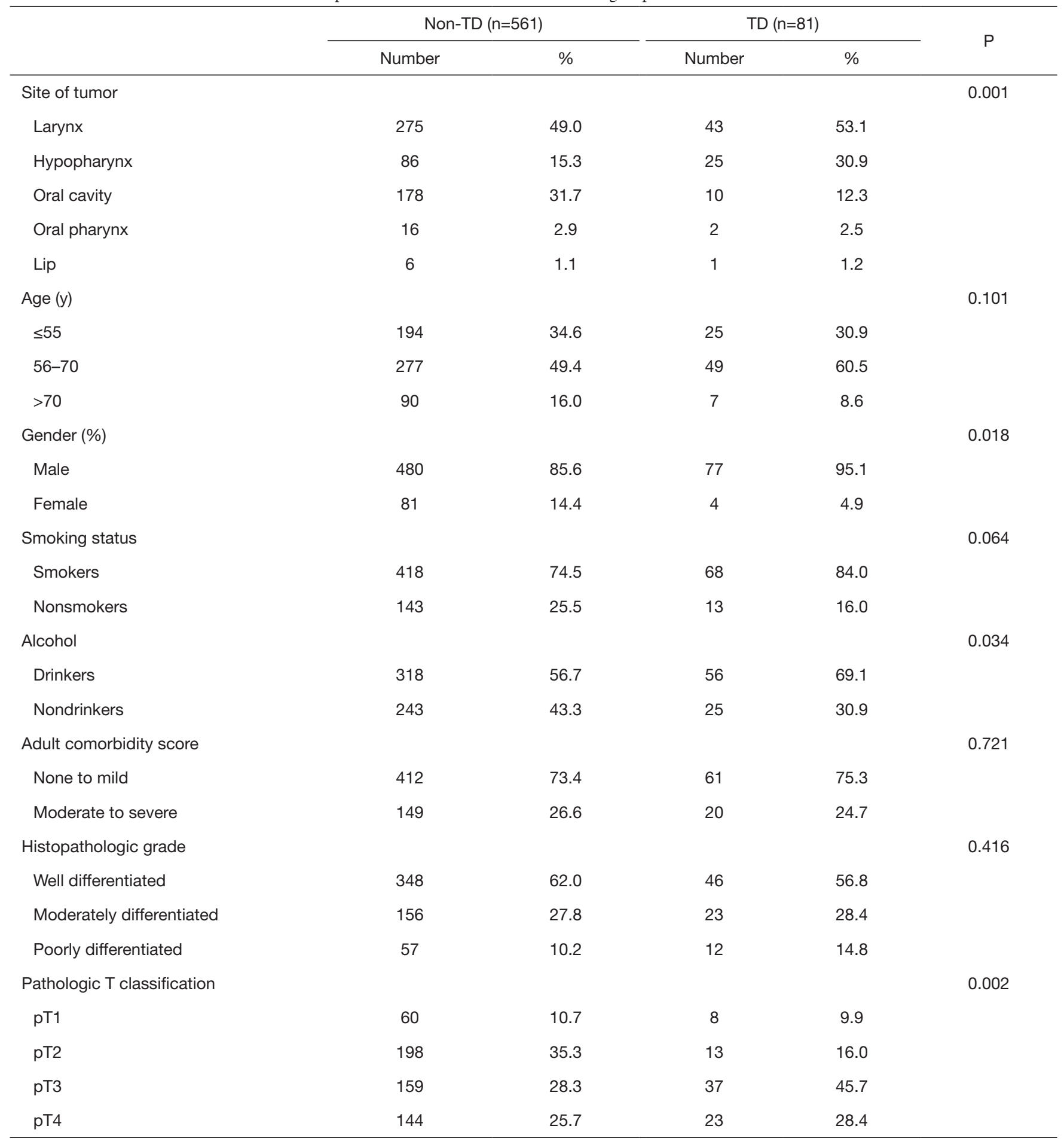

Table 1 (continued) 
Table 1 (continued)

\begin{tabular}{|c|c|c|c|c|c|}
\hline & \multicolumn{2}{|c|}{ Non-TD $(n=561)$} & \multicolumn{2}{|c|}{$\operatorname{TD}(\mathrm{n}=81)$} & $\mathrm{P}$ \\
\hline Pathologic $\mathrm{N}$ classification & & & & & $<0.001$ \\
\hline pNO & 325 & 57.9 & 9 & 11.1 & \\
\hline pN1 & 94 & 16.8 & 11 & 13.6 & \\
\hline pN3 & 1 & 0.2 & 2 & 2.5 & \\
\hline Pathologic stage & & & & & $<0.001$ \\
\hline I & 44 & 7.8 & 0 & 0.0 & \\
\hline II & 116 & 20.7 & 0 & 0.0 & \\
\hline Extranodal extension & & & & & 0.543 \\
\hline Negative & 541 & 96.4 & 77 & 95.1 & \\
\hline Positive & 20 & 3.6 & 4 & 4.9 & \\
\hline Positive margin & & & & & 0.089 \\
\hline Negative & 527 & 93.9 & 72 & 88.9 & \\
\hline Positive & 34 & 6.1 & 9 & 11.1 & \\
\hline Perineural invasion & & & & & 0.393 \\
\hline Negative & 538 & 95.9 & 76 & 93.8 & \\
\hline
\end{tabular}

HNSCC, head and neck squamous cell carcinoma; TD, tumor deposit. P was calculated with the Chi-square test.

maximizing matching performance, 81 patients who had TDs were paired with 70 patients without TDs. Eleven unmatched patients of the non-TD group were eliminated from PSM cohort by the software. After PSM, all the selected characteristics were balanced between the two groups, as shown in Table 3.

After PSM, the 5-year OS rate was $49.5 \%$ and $65.6 \%$ in the TD and non-TD group, respectively. The 5 -year DSS rate was $49.5 \%$ in the TD group compared with $65.6 \%$ in the non-TD group. The 5-year RFS rate was $35.7 \%$ and $61.0 \%$ in the TD and non-TD group, respectively. Significant differences in DSS $(\mathrm{P}=0.040)$ and RFS $(\mathrm{P}=0.004)$ were found between the two groups, as shown in Figure 2.

\section{Discussion}

Since its first description in 1935 , the TD has been investigated in several cancers, and the mechanism underlying its formation is still under debate. At the time of their discovery, TDs were thought to represent tumor cell dissemination along blood vessels (3). Later, some other hypotheses were proposed such as perivascular, intralymphatic/perilymphatic, and perineural pathways. The formation of TDs sometimes results from more than a single pathway (15). Some researchers have proposed that TDs originate from lymph node metastases with thorough extranodal extensions, which eliminate the structure 

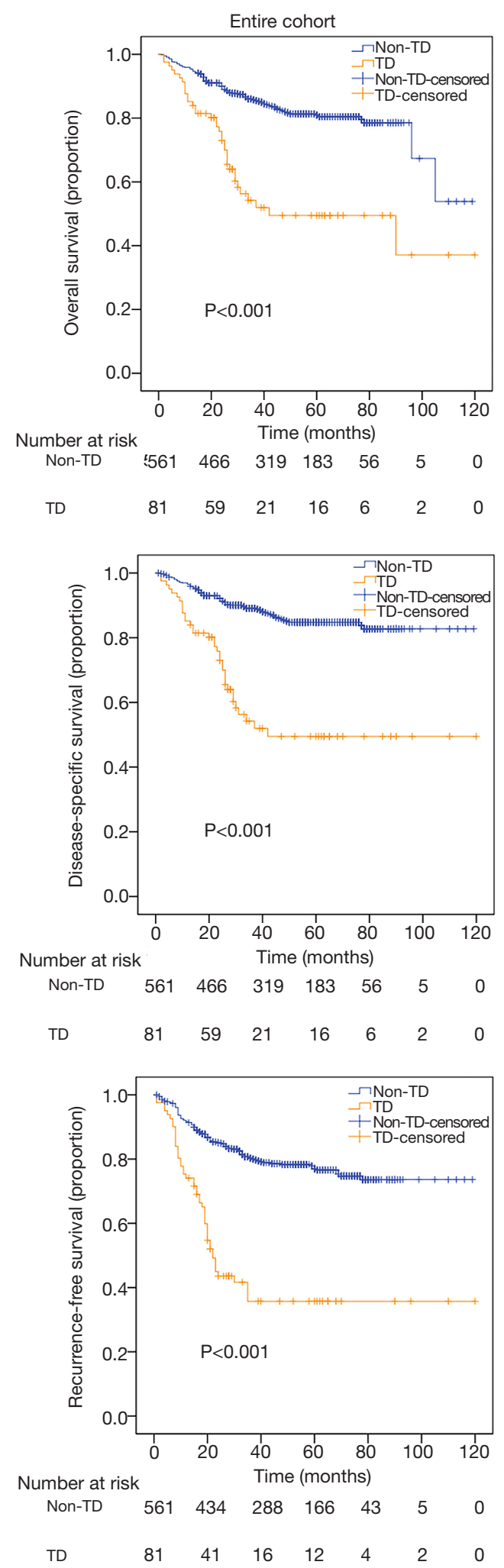

Figure 1 Overall survival (OS), disease-specific survival (DSS), and recurrence-free survival (RFS) in HNSCC patients with and without tumor deposits. HNSCC, head and neck squamous cell carcinoma; TD, tumor deposit. of the primary lymph node. However, this mechanism cannot explain the formation of all TDs based on their morphology. First, trapped nerves and arteries in some TDs are not common structures in lymph nodes $(16,17)$. Second, two kinds of morphologies are detected in TDs: those with and those without regular contours. TDs with regular contours have been thought to originate from lymphatic or perilymphatic pathway, and TDs without regular contours are more likely to originate from vascular or perivascular pathway. The $6^{\text {th }}$ edition of TNM staging for colorectal carcinomas applied such criteria to define TDs. TDs with regular contours were identified as lymph node metastases (18). However, as more studies uncovered the independent prognostic value of TDs (19-21), they were no longer classified according to their shapes or considered as lymph node metastases. Therefore, AJCC counted TDs as the pN1c stage in the $7^{\text {th }}$ edition of TNM staging for colorectal carcinomas (22), which was confirmed in subsequent studies $(8,23,24)$.

According to the few studies in the literature, the reported incidence of TDs in HNSCC is variable. Violaris and colleagues pioneered the study of TDs in HNSCC, in which 138 of 497 patients (27.8\%) had TDs (25). A significantly higher presence of TDs was found in patients with poorly differentiated HNSCC plus T4 tumors. However, the neck dissection samples from these patients were obtained sometime after the initial treatment, so they might have more cervical metastases than patients who had neck dissections during the initial treatment. MacLennan and colleagues analyzed 63 patients with HNSCCs and clinically N0 necks. Five patients $(7.9 \%)$ were identified with TDs (26). They later conducted another study in 155 patients with HNSCCs and found TDs in 37 patients (23.8\%) $(27,28)$. Patients with hypopharynx SCCs were most likely to develop TDs (28). Sarioglu and colleagues retrospectively analyzed neck dissection samples from 140 patients with HNSCCs and found TDs in 24 patients (17.1\%). In their study, patients with TDs were associated with more lymphovascular invasion and a higher pN (29). In the present study, TDs were found in $12.6 \%$ of the patients, which adds to and supports the previous study. In addition, TDs were significantly more common in hypopharynx SCC, males, and drinkers. Patients with TDs were also more likely to exhibit lymphovascular invasion and a higher $\mathrm{pT}, \mathrm{pN}$, and pathologic stage. The characteristics of TDs were partly in accordance with historical data $(25,28,29)$, which might reflect that TDs are indicative of more advanced HNSCC. 
Table 2 Univariable and multivariable analyses of OS, DSS, and RFS regarding tumor deposits and other pathologic factors in the whole cohort

\begin{tabular}{|c|c|c|c|c|c|c|}
\hline & \multicolumn{2}{|l|}{ OS } & \multicolumn{2}{|l|}{ DSS } & \multicolumn{2}{|l|}{ RFS } \\
\hline \multicolumn{7}{|l|}{ Univariable analyses } \\
\hline $\begin{array}{l}\text { Differentiation } \\
\text { (well vs. moderately vs. poorly) }\end{array}$ & $0.569(0.453-0.714)$ & $<0.001$ & $0.457(0.365-0.593)$ & $<0.001$ & $0.581(0.473-0.714)$ & $<0.001$ \\
\hline $\begin{array}{l}\text { Pathologic N-stage } \\
\text { (pN0 vs. pN1 vs. pN2 vs. pN3) }\end{array}$ & $0.603(0.499-0.728)$ & $<0.001$ & $0.482(0.388-0.599)$ & $<0.001$ & $0.501(0.421-0.597)$ & $<0.001$ \\
\hline Pathologic stage (I vs. II vs. III vs. IV) & $0.426(0.327-0.555)$ & $<0.001$ & $0.304(0.213-0.435)$ & $<0.001$ & $0.389(0.304-0.498)$ & $<0.001$ \\
\hline Extranodal extension (Neg. vs. Pos.) & $0.628(0.293-1.345)$ & 0.231 & $0.517(0.240-1.113)$ & 0.092 & $0.336(0.194-0.581)$ & $<0.001$ \\
\hline LVI (Neg. vs. Pos.) & $0.360(0.221-0.586)$ & $<0.001$ & $0.294(0.179-0.482)$ & $<0.001$ & $0.304(0.201-0.460)$ & $<0.001$ \\
\hline Tumor deposit (Pos. vs. Neg.) & $3.211(2.174-4.745)$ & $<0.001$ & $4.205(2.793-6.329)$ & $<0.001$ & $3.955(2.819-5.549)$ & $<0.001$ \\
\hline \multicolumn{7}{|l|}{ Multivariable analyses } \\
\hline $\begin{array}{l}\text { Differentiation } \\
\text { (Well vs. moderately vs. poorly) }\end{array}$ & $0.623(0.489-0.796)$ & $<0.001$ & $0.498(0.381-0.651)$ & $<0.001$ & $0.666(0.532-0.833)$ & $<0.001$ \\
\hline $\begin{array}{l}\text { Pathologic T-stage } \\
\text { (pT1 vs. pT2 vs. pT3 vs. pT4) }\end{array}$ & $1.261(0.982-1.621)$ & 0.068 & & 0.120 & $1.202(0.997-1.449)$ & 0.053 \\
\hline $\begin{array}{l}\text { Pathologic N-stage } \\
\text { (pN0 vs. pN1 vs. pN2 vs. pN3) }\end{array}$ & $1.287(0.975-1.701)$ & 0.076 & & 0.880 & & 0.886 \\
\hline Tumor deposit (Pos. vs. Neg.) & $2.345(1.533-3.587)$ & $<0.001$ & $2.818(1.828-4.345)$ & $<0.001$ & $2.536(1.762-3.650)$ & $<0.001$ \\
\hline
\end{tabular}

OS, overall survival; DSS, disease-specific survival; RFS, recurrence-free survival; PSM, propensity score matching; CI, confidence interval; HR, hazard ratio; LVI, lymphovascular invasion. Pos., positive; Neg., negative.

A large amount of evidence in the literature supports TDs as adverse prognostic factors in colorectal and gastric carcinomas (11,12,30-32). However, a literature search identified only three reports on the independent prognostic significance of TDs in HNSCCs, as defined herein. TDs have been shown to be adverse prognostic factors for OS $(25,28,29)$ and DSS (29). However, two of the studies had a relatively small sample size, and none of the studies adjusted other prognostic factors between the TD group the non-TD group to compare the independent prognostic significance of TDs. Thus, the poor survival of patients with TDs might be the consequence of several confounding factors. In our study, as shown in Table 1, due to the significant differences in several variables between the two groups, multivariable analyses and PSM were applied to exclude potential variables that might impact survival and balance the baseline characteristics between the two groups. In the multivariable analyses, in addition to differentiation, pathologic stage, perineural invasion, and lymphovascular invasion, TDs also had negative effects on OS, DSS, 
Table 3 Baseline characteristics of HNSCC patients between the TD and non-TD group after PSM

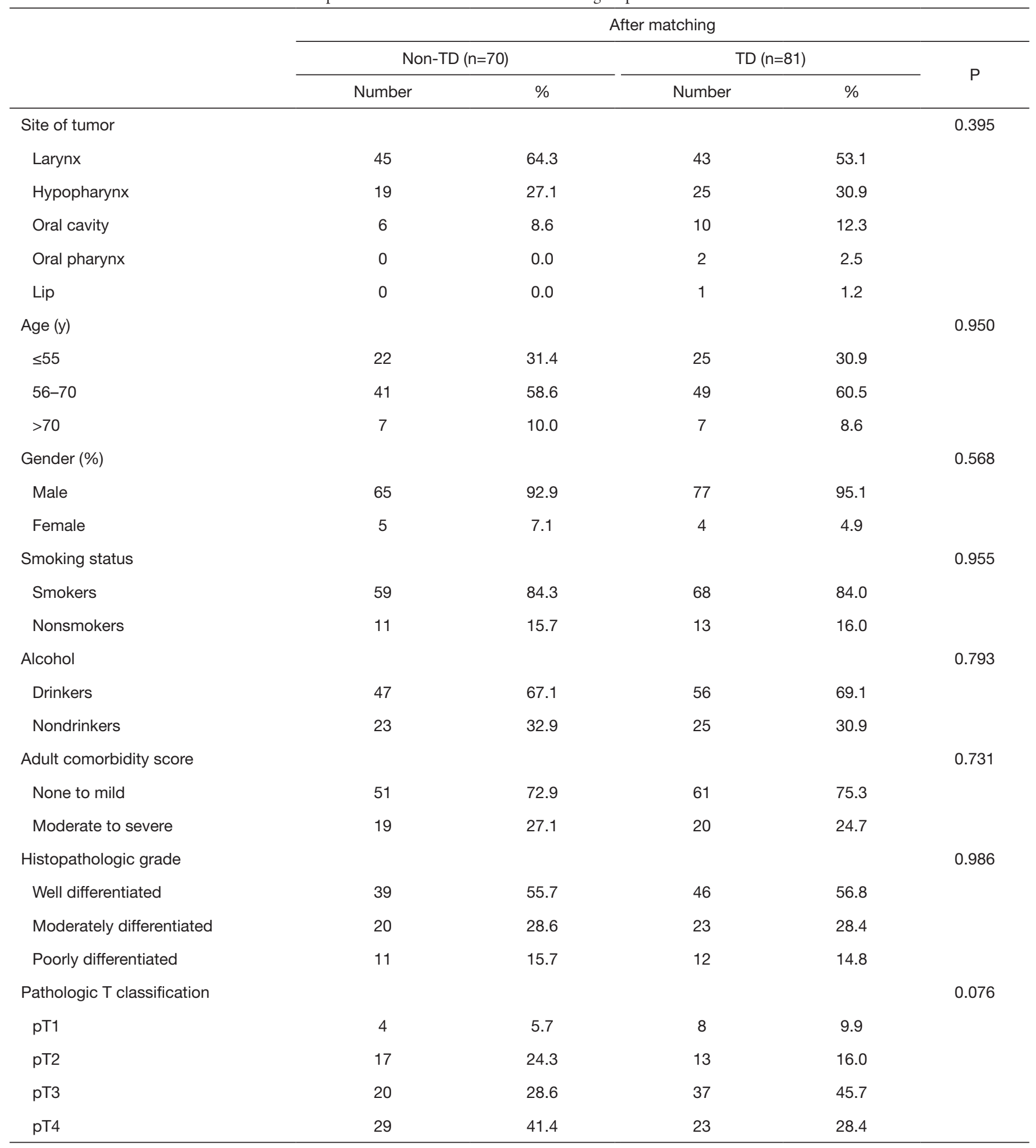

Table 3 (continued) 
Table 3 (continued)

\begin{tabular}{|c|c|c|c|c|c|}
\hline & \multicolumn{5}{|c|}{ After matching } \\
\hline & Number & $\%$ & Number & $\%$ & $\mathrm{P}$ \\
\hline Pathologic $\mathrm{N}$ classification & & & & & 0.496 \\
\hline $\mathrm{pNO}$ & 11 & 15.7 & 9 & 11.1 & \\
\hline $\mathrm{pN} 2$ & 49 & 70.0 & 59 & 72.8 & \\
\hline $\mathrm{pN} 3$ & 0 & 0.0 & 2 & 2.5 & \\
\hline Pathologic stage & & & & & 0.071 \\
\hline I & 0 & 0.0 & 0 & 0.0 & \\
\hline IV & 61 & 87.1 & 72 & 88.9 & \\
\hline Extranodal extension & & & & & 0.514 \\
\hline Negative & 68 & 97.1 & 77 & 95.1 & \\
\hline Positive & 2 & 2.9 & 4 & 4.9 & \\
\hline Positive margin & & & & & 0.122 \\
\hline Negative & 67 & 95.7 & 72 & 88.9 & \\
\hline Positive & 3 & 4.3 & 9 & 11.1 & \\
\hline Perineural invasion & & & & & 0.334 \\
\hline
\end{tabular}

HNSCC, head and neck squamous cell carcinoma; TD, tumor deposit; PSM, propensity score matching. P was calculated with the Chisquare test.

and RFS. In the PSM cohort, the TD group tended to have diminished DSS and RFS rates $(\mathrm{P}=0.040$ and 0.004 , respectively), supporting the $\mathrm{TD}$ as an independent adverse prognostic factor in HNSCC.

Although this is not the pilot study to reveal the effects of TDs on survival in HNSCC, our study had a relatively larger sample size and applied a strict statistical approach. The presence and adverse prognostic effects of TDs were further confirmed. As TDs have not become an established part of the pathology report in HNSCC, it is important to establish uniform terminology for the detection and report of TDs among histopathologists. The TD identifies patients with poor chances of long-term survival. Therefore, more attention should be focused on TDs among pathologists, oncologists, and surgeons. Future research with more patients is required to incorporate TDs into pathological staging systems.

\section{Conclusions}

In conclusion, the present study proposed the TD as an independent poor prognostic factor meriting further 

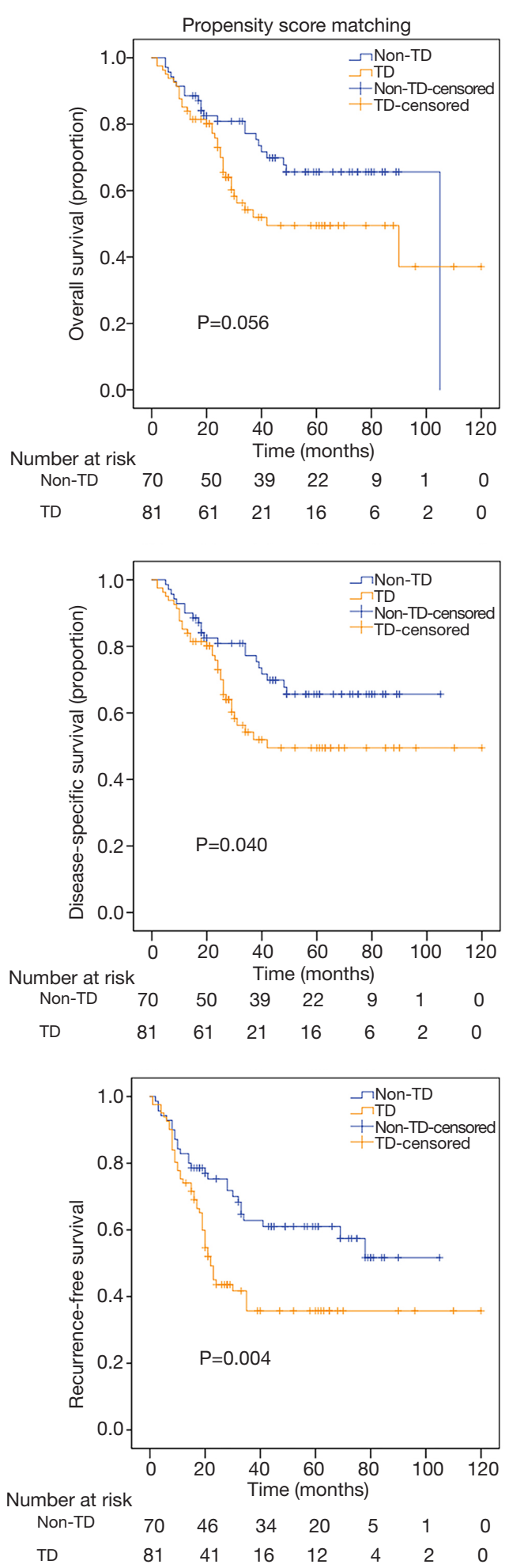

Figure 2 Overall survival (OS), disease-specific survival (DSS), and recurrence-free survival (RFS) in HNSCC patients with and without tumor deposits, after propensity score matching. HNSCC, head and neck squamous cell carcinoma; TD, tumor deposit; PSM, propensity score matching. research because of its association with diminished OS, DSS and RFS rates in HNSCC patients. Poorer DSS and RFS rates were also observed in patients with TDs using PSM.

\section{Acknowledgments}

We would like to thank American Eagle Editing Office for their help in polishing the language of our paper.

Funding: This work was supported by the National Natural Science Foundation of China (grant number 81273173).

\section{Footnote}

Reporting Checklist: The authors have completed the STROBE reporting checklist. Available at http://dx.doi. org/10.21037/atm-20-4369

Data Sharing Statement: Available at http://dx.doi. org/10.21037/atm-20-4369

Conflicts of Interest: All authors have completed the ICMJE uniform disclosure form (available at http://dx.doi. org/10.21037/atm-20-4369). The authors have no conflicts of interest to declare.

Ethical Statement: The authors are accountable for all aspects of the work in ensuring that questions related to the accuracy or integrity of any part of the work are appropriately investigated and resolved. The study was conducted in accordance with the Declaration of Helsinki (as revised in 2013). The current study was approved by the Ethics Committee of Peking Union Medical College Hospital (NO: S-K1243), Peking Union Medical College and Chinese Academy of Medical Sciences, Beijing, China. Individual consent for this retrospective analysis was waived. The study outcomes will not affect the future management of the patients.

Open Access Statement: This is an Open Access article distributed in accordance with the Creative Commons Attribution-NonCommercial-NoDerivs 4.0 International License (CC BY-NC-ND 4.0), which permits the noncommercial replication and distribution of the article with the strict proviso that no changes or edits are made and the original work is properly cited (including links to both the formal publication through the relevant DOI and the license). See: https://creativecommons.org/licenses/by-nc-nd/4.0/. 


\section{References}

1. Bray F, Ferlay J, Soerjomataram I, et al. Global cancer statistics 2018: GLOBOCAN estimates of incidence and mortality worldwide for 36 cancers in 185 countries. CA Cancer J Clin 2018;68:394-424.

2. Gupta B, Johnson NW, Kumar N. Global Epidemiology of Head and Neck Cancers: A Continuing Challenge. Oncology 2016;91:13-23.

3. Gabriel WB, Dukes C, Bussey HJR. Lymphatic spread in cancer of the rectum. Br J Surg 1935;23:395-413.

4. Washington MK, Berlin J, Branton P, et al. Protocol for the examination of specimens from patients with primary carcinoma of the colon and rectum. Arch Pathol Lab Med 2009; 133:1539-51.

5. Goldstein NS, Turner JR. Pericolonic tumor deposits in patients with $\mathrm{T} 3 \mathrm{~N}+\mathrm{MO}$ colon adenocarcinomas: markers of reduced disease free survival and intra-abdominal metastases and their implications for TNM classification. Cancer 2000;88:2228-38.

6. Puppa G, Maisonneuve P, Sonzogni A, et al. Pathological assessment of pericolonic tumor deposits in advanced colonic carcinoma: relevance to prognosis and tumor staging. Mod Pathol 2007;20:843-55.

7. Ueno H, Mochizuki H, Shirouzu K, et al. Multicenter study for optimal categorization of extramural tumor deposits for colorectal cancer staging. Ann Surg 2012;255:739-46.

8. Nagtegaal ID, Knijn N, Hugen N, et al. Tumor Deposits in Colorectal Cancer: Improving the Value of Modern Staging-A Systematic Review and Meta-Analysis. J Clin Oncol 2017;35:1119-27.

9. Jin M, Roth R, Rock JB, et al. The impact of tumor deposits on colonic adenocarcinoma AJCC TNM staging and outcome. Am J Surg Pathol 2015;39:109-15.

10. Edge S, Byrd D, Compton C, et al. AJCC cancer staging manual. 7th ed New York. NY: Springer 2010:57-67.

11. Ersen A, Unlu MS, Akman T, et al. Tumor deposits in gastric carcinomas. Pathol Res Pract 2014;210:565-70.

12. Sun Z, Wang ZN, Xu YY, et al. Prognostic significance of tumor deposits in gastric cancer patients who underwent radical surgery. Surgery 2012;151:871-81.

13. Puppa G, Ueno H, Kayahara M, et al. Tumor deposits are encountered in advanced colorectal cancer and other adenocarcinomas: an expanded classification with implications for colorectal cancer staging system including a unifying concept of in-transit metastases. Mod Pathol 2009;22:410-5.
14. Piccirillo JF, Lacy PD, Basu A, et al. Development of a new head and neck cancer-specific comorbidity index. Arch Otolaryngol Head Neck Surg 2002;128:1172-9.

15. Nagtegaal ID, Quirke P. Colorectal tumour deposits in the mesorectum and pericolon; a critical review. Histopathology 2007;51:141-9.

16. Rock JB, Washington MK, Adsay NV, et al. Debating deposits: an interobserver variability study of lymph nodes and pericolonic tumor deposits in colonic adenocarcinoma. Arch Pathol Lab Med 2014;138:636-42.

17. Gonzalez RS, Liu EH, Alvarez JR, et al. Should mesenteric tumor deposits be included in staging of well-differentiated small intestine neuroendocrine tumors? Mod Pathol 2014;27:1288-95.

18. Greene F, Page D, Fleming I. AJCC Cancer Staging Manual, 6th edn, Vol. Springer: New York; 2002.

19. Ono C, Yoshinaga K, Enomoto M, et al. Discontinuous rectal cancer spread in the mesorectum and the optimal distal clearance margin in situ. Dis Colon Rectum 2002;45:744-9; discussion 742-3.

20. Ueno H, Mochizuki H, Shirouzu K, et al. Actual status of distribution and prognostic impact of extramural discontinuous cancer spread in colorectal cancer. J Clin Oncol 2011;29:2550-6.

21. Shimada Y, Takii Y. Clinical impact of mesorectal extranodal cancer tissue in rectal cancer: detailed pathological assessment using whole-mount sections. Dis Colon Rectum 2010;53:771-8.

22. Edge SB, Compton CC. The American Joint Committee on Cancer: the 7th edition of the AJCC cancer staging manual and the future of TNM. Ann Surg Oncol 2010;17:1471-4.

23. Wünsch K, Muller J, Jahnig H, et al. Shape is not associated with the origin of pericolonic tumor deposits. Am J Clin Pathol 2010;133:388-94.

24. Wei XL, Qiu MZ, Zhou YX, et al. The clinicopathologic relevance and prognostic value of tumor deposits and the applicability of N1c category in rectal cancer with preoperative radiotherapy. Oncotarget 2016;7:75094-103.

25. Violaris NS, O'Neil D, Helliwell TR, et al. Soft tissue cervical metastases of squamous carcinoma of the head and neck. Clin Otolaryngol Allied Sci 1994;19:394-9.

26. Coatesworth AP, MacLennan K. Squamous cell carcinoma of the upper aerodigestive tract: the prevalence of microscopic extracapsular spread and soft tissue deposits in the clinically N0 neck. Head Neck 2002;24:258-61.

27. Jose J, Coatesworth AP, Johnston C, et al. Cervical node metastases in squamous cell carcinoma of the upper 
aerodigestive tract: the significance of extracapsular spread and soft tissue deposits. Head Neck 2003;25:451-6.

28. Jose J, Moor JW, Coatesworth AP, et al. Soft tissue deposits in neck dissections of patients with head and neck squamous cell carcinoma: prospective analysis of prevalence, survival, and its implications. Arch Otolaryngol Head Neck Surg 2004;130:157-60.

29. Sarioglu S, Akbulut N, Iplikci S, et al. Tumor deposits in head and neck carcinomas. Head Neck 2016;38 Suppl 1:E256-60.

30. Nagayoshi K, Ueki T, Nishioka Y, et al. Tumor deposit

Cite this article as: Yu S, Zhu Y, Shi X, Diao W, Zhu X, Gao Z, Chen X. The prognostic significance of tumor deposits in patients with head and neck squamous cell carcinomas. Ann Transl Med 2021;9(5):377. doi: 10.21037/atm-20-4369 is a poor prognostic indicator for patients who have stage II and III colorectal cancer with fewer than 4 lymph node metastases but not for those with 4 or more. Dis Colon Rectum 2014;57:467-74.

31. Anup S, Lu J, Zheng CH, et al. Prognostic significance of perigastric tumor deposits in patients with primary gastric cancer. BMC Surg 2017;17:84.

32. Lee HS, Lee HE, Yang HK, et al. Perigastric tumor deposits in primary gastric cancer: implications for patient prognosis and staging. Ann Surg Oncol 2013;20:1604-13. 